\title{
ANÁLISIS CRÍTICO DE LOS DERECHOS DE LOS EXTRANJEROS PRIVADOS DE LIBERTAD EN ESPAÑA
}

\author{
CRITICAL ANALYSIS OF THE RIGHTS OF FOREIGNERS DEPRIVED \\ OF LIBERTY IN SPANISH PRISONS
}

Cristina Santacruz Iglesias Universidad Miguel Hernández, Elche. España/Spain cristisantacruz@,hotmail.com

Recibido/Received: 11/08/2014

Modificado/Modified: 19/08/2014

Aceptado/Accepted: 30/09/2014

\section{RESUMEN}

El análisis crítico de los derechos de los extranjeros privados de libertad en España es donde se inserta el presente estudio, con el objetivo de analizar de forma crítica el sistema normativo vigente y sus repercusiones -desde el punto de vista legal- sobre los extranjeros que cumplen sanciones privativas de libertad en algún Centro Penitenciario español. Para ello también será objeto de análisis el perfil de la población en cárceles españolas, así como consecuencias jurídicas de la excarcelación.

\section{PALABRAS CLAVE}

Inmigración, prisión, delincuencia, sustitución, expulsión.

\section{SUMARIO}

1. Introducción. 2. Metodología. 3. Análisis del perfil general de la población extranjera en prisiones españolas. 4. Estudio de los derechos reconocidos a los extranjeros en prisión. 5. Consecuencias de la excarcelación. 6. Conclusiones. Bibliografía

\section{ABSTRACT}

The critical analysis of the rights of foreigners detained in Spain is where this study is inserted, in order to critically analyze the existing regulatory system and its implications -from a legal point of view- of foreigners compliant custodial sentences in a Spanish Prison. To that end, we will analyze the profile of the Spanish population in prisons and legal consequences of the release.

\section{KEYWORDS}

Immigration, prison, delinquency, replacement, expulsion.

\section{CONTENTS}

1. Introduction. 2. Methodology. 3. Analysis of general profile of the foreign population in Spanish prisons. 4. Study of the rights granted to foreigners in prison. 5. Consequences of the release. 6. Conclusions. References 


\section{INTRODUCCIÓN}

España se ha visto inmersa en estos últimos años en un proceso de cambio social importante. La llegada de inmigrantes ha sido un factor clave que, en un primer momento, contribuyó al florecimiento de la economía española y que hoy, en plena crisis, han sido los primeros afectados al quedar fuera del sistema legal. Muchos de ellos en situaciones de precariedad, e incluso de exclusión. Y no olvidemos que se trata de miles de personas que llegaron a nuestro país con la intención de trabajar, huyendo de la miseria y pobreza de sus países de origen.

El aumento de la población migrante en los últimos años ha conllevado, lógicamente, a una mayor presencia extranjera en las instituciones penitenciarias españolas. Al mismo tiempo, la legislación respecto a esta materia ha sufrido reiteradas e importantes reformas. Estas reformas normativas, y fundamentalmente los cambios introducidos por LO 11/2003, (en adelante, LO 11/2003), han incidido en los cambios de la política penal concerniente a los extranjeros que cometen delitos, como en algunos aspectos del cumplimiento de la pena.

Desde la primera redacción de la Ley Orgánica 4/2000, de 11 de enero, sobre derechos y libertades de los extranjeros en España y su integración social, aprobado por el Real Decreto $557 / 2011$, de 20 de abril, publicado en el BOE n ${ }^{\circ} 262$ del pasado día 1 de noviembre de 2013 (en adelante LOEX) el sistema penitenciario español ha declarado su desconfianza ante el fenómeno de la delincuencia de los extranjeros a través de la creación de una serie de normas que impidan su establecimiento en el país y que procuren su expulsión.

Esta ley, que ha sufrido numerosas modificaciones, la más reciente con el Real Decreto 844/2013, de 31 de octubre, por el que se modifica el Reglamento de la LOEX y que como muy bien apunta Cristina Rodríguez Yagüe, "El modelo de política migratoria diseñado por el legislador en la LOEX responde a la ordenación de los flujos migratorios de carácter eminentemente laboral $\mathrm{y}$, por tanto, se encuentra condicionado a las necesidades de la situación nacional de empleo, si bien confluyen otros fines que acompañan a éste y que, con la reforma operada por la LO 2/2009, de 11 de diciembre, han querido pasar a un plano de mayor relevancia. Se trata de una regulación administrativa dirigida hacia una migración fundamentalmente de carácter económico y frente a la que el legislador opta por la selección del perfil de extranjero al que necesita y, por ende permite, su entrada, estancia y desempeño de un trabajo en territorio español y al que le reconoce el ejercicio pleno de derechos en tanto se encuentra en una situación de regularidad administrativa."

Por otro lado, el Código penal de 1995, reformado por LO 11/2003 de 29 de septiembre y posteriormente por la LO 5/2010 de 22 de junio ha instaurado la expulsión como respuesta sustitutiva a las penas privativas de libertad dentro de una serie de medidas que en definitiva dificulten el acceso y permanencia de inmigrantes con antecedentes penales.

Sin embargo, no podemos perder de vista que la Constitución Española de 1978 (en adelante CE) contempla una serie de derechos fundamentales a todos los ciudadanos dotándonos a todos los mismos derechos por igual. Sin embargo, no todos los ciudadanos pueden poner en práctica todos esos derechos en medida en que quisieran. Sin duda estamos hablando de las personas extranjeras, en especial de las personas extranjeras en prisión, que debido a sus circunstancias particulares ve como sus derechos quedan mermados, incluso a veces quedando totalmente anulados.

Los internos extranjeros han de recibir un trato igual que el resto de los presos nacionales debido a que partiendo de la $\mathrm{CE}$, en cuanto a la reinserción social de los penados a penas privativas de libertad no hace distinción entre nacionales y extranjeros, las penas de unos y otros han de tener la mismo objetivo, y cumplirse en igualdad de condiciones. Hay que tener 
en cuenta que el extranjero en prisión no solo se enfrenta a un gran cambio de adaptación y asimilación de nuestra cultura, religión y educación, sino al abandono en muchos casos de sus valores y de su propia identidad.

Si a esto le añadimos el desconocimiento del idioma que, como ya veremos, puede repercutir en el conocimiento y disfrute de sus derechos, así como en una inadaptación con respecto a los demás reclusos tenemos un desarraigo total y absoluto del extranjero privado de libertad.

Este desarraigo social y familiar les va impedir o al menos dificultar el disfrute de los mecanismos que posibilitan un contacto con la sociedad como son los permisos penitenciarios, el tercer grado o el acceso a la libertad condicional.

En definitiva el interno extranjero se encuentra en una situación indiscutiblemente excluyente por partida doble, como extranjero y como recluso. Es importante dejar sentado que en este trabajo se hace referencia en todo caso a los extranjeros de origen extracomunitario, ya que las repercusiones en el estatuto administrativo tienen difícil extensión a los extranjeros comunitarios, debido a su derecho a la libre circulación y residencia por el territorio de la UE.

Es en este complicado entorno jurídico se inserta el presente estudio, con el objetivo de analizar de forma crítica el sistema normativo vigente y sus repercusiones -desde el punto de vista legal- sobre los extranjeros que cumplen sanciones privativas de libertad en algún Centro Penitenciario español.

\section{METODOLOGÍA}

La metodología empleada combina el estudio de la situación de los extranjeros encarcelados en España respecto a la población penal española, con el análisis normativo y de la jurisprudencia española relacionada con el tema, así como un análisis bibliográfico que ha permitido detectar las carencias del sistema y poner sobre el tapete la situación de inferioridad jurídica en la que se encuentran estas personas frente a la Administración española.

Qué duda cabe que España debido a su situación geográfica estratégica es una puerta de entrada en Europa para inmigrantes sobre todo procedentes de África y Sudamérica. Sin embargo, muchos de estos inmigrantes no vienen a España a asentarse, sino que una vez han entrado en España, la barrera para la movilidad dentro de la Unión Europea es mínima y pueden moverse por los estados miembros casi sin dificultad. Es por ello que la legislación española necesita una coordinación en lo que se refiere a política migratoria con la Unión Europea.

\section{ANÁlisis DEL PERFIL GENERAL DE LA POBLACIÓN EXTRANJERA EN PRISIONES ESPAÑOLAS}

Es de vital importancia tener claro y no confundir los Centros de Internamiento de Extranjeros (CIE) con las Instituciones penitenciarias, ya que los CIE son establecimientos públicos no penitenciarios donde se priva de libertad a personas extranjeras por una falta administrativa generalmente por encontrarse en situación irregular y no por haber cometido un delito. A lo largo de este estudio únicamente abordaremos el tema de la situación los reclusos extranjeros privados de libertad en instituciones penitenciarias. 
Para dar comienzo al análisis de los derechos de los extranjeros privados de libertad en España debemos realizar la siguiente pregunta: ¿A quién se considera extranjero? Esta pregunta tiene su respuesta en el artículo 1.1 de la Ley Orgánica 4/2000, de 11 de enero, sobre derechos y libertades de los extranjeros en España y su integración social, que dispone que "Se consideran extranjeros, a los efectos de la aplicación de la presente Ley, a los que carezcan de la nacionalidad española." Sin embargo, existe un sinfín de situaciones diferenciadas en las que una persona puede considerarse extranjero.

Aunque a lo largo de los tiempos ha habido diferentes normas que regulaban diversos aspectos sobre extranjería, no fue hasta 1985 con la promulgación de la primera Ley de extranjería, cuando se crea Ley Orgánica 7/1985 de 1 de Julio que serviría de soporte legal a todas las posteriores normas en materia de extranjería.

Tras varios años y un cambio de gobierno, llegaría la Ley Orgánica 4/2000, de 11 de enero que supone un gran avance respecto a la norma anterior, pero que deja en entredicho muchas cuestiones esenciales.

En los años siguientes y tras un incremento de la población extranjera en España, que analizaremos más adelante, queda de manifiesto la necesidad de modificación la Ley Orgánica 4/2000, de 11 de enero.

La entrada en vigor de la Ley Orgánica 5/2010 del 22 de junio, constituyó una gran reforma del Código Penal, ya que se introducía la posibilidad de reducir en un grado ciertas conductas contra la salud pública. Este sistema, que lo único que pretende es impedir, o cuanto menos dificultar que los extranjeros, y a la vez reclusos, puedan continuar en España si no cumplen los requisitos legales para poder permanecer en el territorio nacional.

Teniendo en cuenta los datos estadísticos existentes es evidente que el número de extranjeros en España ha crecido desde los últimos 15 años. La buena situación económica en la que permaneció España durante varios años, ha convertido a nuestro país en uno de los países que más inmigrantes recibe de la Unión Europea.

Actualmente y debido a la crisis económica, que sufrimos desde hace ya más de cinco años, a la falta de expectativas laborales y al cambio en la legislación, han hecho que esta tendencia al incremento de la población mermara sustancialmente en los últimos años. Asimismo, y teniendo en cuenta la relación existente entre población extranjera y reclusos extranjeros, la población extranjera reclusa también ha padecido un descenso considerable por diferentes razones.

\section{A) Evolución de la población extranjera presa en España respecto a los presos nacionales}

Según la Agrupación de Cuerpos de la Administración de Instituciones Penitenciarias (en adelante ACAIP), "la caída de personas presas ha sido mayor si tenemos en cuenta los años anteriores. La cifra de reclusos se ha reducido en 7.482 sólo en los dos últimos años. Más de la mitad eran internos foráneos que han acogido a la posibilidad de conmutar sus penas a cambio de ser expulsados de España. En concreto los extranjeros han representado el 56,92\% de la bajada total de presos, con 4.259 internos. Así se desprende de las estadísticas de la Secretaría General de Instituciones Penitenciarias".

La cantidad total de reclusos extranjeros en España en 2012 era de 24.036 la cual representaba el 33,93\% del total de población reclusa total.

\section{B) Perfil por áreas geográficas de procedencia de los extranjeros}

Es importante saber el origen de la población reclusa extranjera en cuanto a nacionalidad se refiere, ya que será determinante para saber el nivel de integración en la cultura española, 
que además, en muchas ocasiones, provocará un paulatino aislamiento de recluso en la prisión.

En cuanto al origen mayoritario de los reclusos extranjeros podemos afirmar, según los datos contrastados con la Secretaría General de Instituciones Penitenciarias, con fecha 1 de junio de 2013 y el ACAIP, que las nacionalidades más representativas en los últimos años son los reclusos procedentes de Marruecos y Colombia.

La gran variedad lingüística de todas estas nacionalidades, el analfabetismo de muchos de los reclusos y la falta de respuesta rápida por parte de la Administraciones, no hará sino dificultar, en gran medida, la vida cotidiana del interno extranjero.

\section{C) Perfil de la población reclusa extranjera por Comunidad Autónoma}

Según los datos aportados por la Agrupación de Cuerpos de la Administración de Instituciones Penitenciarias, "Actualmente, en los centros penitenciarios de las Comunidades Autónoma nos encontramos con una población extranjera que representa, respecto al total de presos de esa comunidad, los siguientes datos: el 49,47\% de los presos de Madrid son extranjeros; 48,90\% Castilla y León; 45,67\% Cataluña; 42,63\% Aragón; 42,44\% Melilla; 39,38\% La Rioja; 38,05\% Baleares; 37,14\% Ceuta; 35,91\% Castilla La Mancha; 26,07\% Galicia; 24,30\% Canarias; 20,17\% Andalucía; 20,03\% Extremadura; 18,44\% Cantabria; $11,07 \%$ Asturias.

Las zonas turísticas con más opciones y posibilidades para trabajar, en la construcción y el sector hotelero, Madrid, Levante, Andalucía y en regiones dedicadas a la agricultura como la Costa Levantina, son las zonas con más porcentaje de reclusos extranjeros.

\section{D) Perfil del preso extranjero por edad}

La gran mayoría de los reclusos extranjeros privados de libertad tienen menos de 40 años de edad con un $57,7 \%$. Le siguen personas entre 20 y 25 años con un $12,66 \%$. Por tanto, y en base a estos datos podemos decir que, la población reclusa extranjera es joven, debido a que está íntimamente relacionada con la menor edad de los inmigrantes en general, y por supuesto con otros factores de tipo socio-cultural.

Podemos observar en este caso que la media de edad de población extranjera reclusa, son jóvenes en edad de trabajar.

\section{E) Perfil de la población reclusa extranjera por sexo}

Es evidente, según los datos aportados por ACAIP, que el sexo masculino ha monopolizado las cárceles españolas a lo largo de los años, quedando la mujer en un segundo plano. Sin embargo la presencia femenina, en su mayoría de origen colombiano, rumano y venezolano, en las cárceles españolas crece lentamente incluso por encima de las presas de nacionalidad española.

Con un sistema penitenciario creado por y para los hombres, la población femenina, y en concreto la población femenina extranjera sufre las consecuencias de ser parte de una minoría penitenciaria. Una de estas consecuencias, es sin duda la falta centros especializados para este colectivo, que aunque en minoría, no debería ser menos importante que la población masculina penitenciaria. 


\section{ESTUDIO DE LOS DERECHOS RECONOCIDOS A LOS EXTRANJEROS EN PRISIÓN}

En lo concerniente a este tema examinaremos la importancia de la situación administrativa de los internos extranjeros privados de libertad y su consiguiente condición de regularidad o de irregularidad.

Haremos un desglose de los derechos de este colectivo centrándonos en algunos de estos derechos. Empezaremos con un análisis crítico sobre el derecho a la información, a la educación y a la asistencia sanitaria, para continuar por el derecho a la documentación, a los permisos de salida y a la libertad condicional. En último término examinaremos el derecho al trabajo.

\section{A) Importancia de la situación administrativa de los reclusos extranjeros en prisión}

Diferencia entre regular e irregular.

Por un lado, se considera extranjero regular a la persona que tenga su documentación en regla, ya esté de viaje de vacaciones, estudiando o residiendo.

Por otra parte, se considerará extranjero irregular a la persona que no disponga de documentación, que dicha documentación no esté actualizada por cualquier causa, por haber entrado con visado de turista y una vez dentro del territorio nacional decidiera quedarse sin la autorización de residencia en el plazo legal, por no haber renovado dicha residencia y una serie de casos similares.

De hecho, en la realidad de nuestro sistema penitenciario, existe una extensa variedad en cuanto a la situación documental de los presos extranjeros se refiere. Nos encontramos con reclusos extranjeros con la documentación totalmente en regla, otros que aunque cuando entran en prisión la tienen en regla, se les caduca dentro de prisión, sin ninguna oportunidad de renovación, otras con NIE, otras que ni siquiera saben en qué situación están.

Dependiendo por tanto, de en qué situación administrativa se encuentre el preso tendrá una serie de derechos que aunque, en teoría no debieran ser diferentes de los que prevén nuestras leyes para los reclusos nacionales, queda bastante alejado de la realidad. A pesar de todas las Leyes, Tratados, Decretos y Reglamentos existentes en esta materia, no es suficiente, dada la gran heterogeneidad del tratamiento que debe darse a cada recluso extranjero según la situación administrativa en la que se encuentre.

Legalmente tanto internos españoles como extranjeros gozan de los mismos derechos aunque, a estos últimos se les confiere algunos matices específicos que regulados en Leyes y Reglamentos.

El artículo 25.2 Reglamento Penitenciario argumenta que "Las penas privativas de libertad y las medidas de seguridad estarán orientadas hacia la reeducación y reinserción social y no podrán consistir en trabajos forzados. El condenado a pena de prisión que estuviere cumpliendo la misma gozará de los derechos fundamentales de este Capítulo, a excepción de los que se vean expresamente limitados por el contenido del fallo condenatorio, el sentido de la pena y la Ley penitenciaria. En todo caso, tendrá derecho a un trabajo remunerado y a los beneficios correspondientes de la Seguridad Social, así como al acceso a la cultura y al desarrollo integral de su personalidad."

El artículo 13 de la Constitución Española establece que, "Los extranjeros gozarán en España de las libertades públicas que garantiza el presente Título en los términos que establezcan los Tratados y la ley".

Ignacio Gutiérrez Gutiérrez, en su estudio "Constitución Española, derechos de los extranjeros" argumenta que "Ello no puede significar que son titulares de los derechos 
fundamentales en la medida en que se los reconozca la Ley, porque supondría una contradicción lógica: no serían éstos verdaderos derechos fundamentales. Si la Ley los concediera, y no la Constitución, podría la Ley también suprimirlos. El Tribunal Constitucional, en la Sentencia 115/1987, estableció que en España los extranjeros sí tienen derechos fundamentales."

No obstante, la situación administrativa, social y jurídica puede influir en la estancia del recluso extranjero en prisión de una manera negativa, es decir, su situación podría convertirse en lo que muchas personas llamarían discriminación.

La Ley de Extranjería, dependiendo si el extranjero penado es regular o irregular, se pronunciará respecto al goce de los derechos y libertades. Ejemplo de ello son los derechos de la educación, a la asistencia sanitaria, y al trabajo.

\section{B) Derechos de los extranjeros en prisión}

La base fundamental para el estudio del régimen jurídico de los derechos y libertades de los extranjeros en España se encuentra recogida en la nuestra Constitución.

El artículo 13 de nuestra CE, establece que "Los extranjeros gozarán en España de las libertades públicas que garantiza el presente Título en los términos que establezcan los tratados y la Ley". Aunque en su apartado 2 añade una excepción a este derecho: "Solamente los españoles serán titulares de los derechos reconocidos en el artículo 23, salvo lo que, atendiendo a criterios de reciprocidad, pueda establecerse por tratado o ley para el derecho de sufragio activo y pasivo en las elecciones municipales".

Además según la $\mathrm{CE}$ en su artículo 1, del Título 1, "De los derechos y deberes fundamentales", articula que "La dignidad de la persona, los derechos inviolables que le son inherentes, el libre desarrollo de la personalidad, el respeto a la ley y a los derechos de los demás son fundamento del orden político y de la paz social".

A pesar de que estos preceptos anteriormente mencionados han sido desarrollados por otras Leyes y Reglamentos, será la jurisprudencia la que nos diga realmente que derechos son los destinados a los extranjeros

Por una parte, el derecho a la vida y a la integridad física y moral, a la intimidad personal y familiar son algunos de los derechos que se reservan a nacionales y extranjeros en igualdad de condiciones. Asimismo, la ley contempla otros derechos, como el derecho de asistencia sanitaria de urgencia, a la documentación, los derechos de acceso a la enseñanza obligatoria, a los servicios sociales básicos y la asistencia jurídica gratuita, que también se prevé para los extranjeros indistintamente de la situación administrativa del interno extranjero.

Por el contrario, para el goce de derechos, como el de reunión o manifestación, asociación, trabajo, seguridad social, será necesario cumplir una serie de requisitos, es decir, la situación administrativa del recluso será condicionante para el disfrute de estos derechos.

Anteriormente con la Ley 7/1985, los derechos reconocidos a los extranjeros eran muy limitados, aunque se ampliaron con posterioridad a la entrada en vigor de la Ley 4/2000, que diferenciaba entre irregulares, residentes legales y extranjeros empadronados. Pero fue a través de diferentes Sentencias (STC236/2007) lo que sentó la base para la posterior modificación de la Ley Orgánica 2/2009 de 11 de diciembre que ampliaba los derechos de los extranjeros.

Ciertamente analizar todos y cada uno de estos derechos nos llevaría una eternidad, por lo que solo nos centraremos en algunos de ellos. 
B.1. Derecho a la información.

El Reglamento Penitenciario dispone de varios procedimientos especiales en relación con los derechos de los internos extranjeros.

El artículo 52 del Reglamento Penitenciario dispone que:

1. "Los internos recibirán a su ingreso información escrita sobre sus derechos y deberes, el régimen del Establecimiento, las normas disciplinarias y los medios para formular peticiones, quejas y recursos. Con este fin, se les entregará un ejemplar de la cartilla o folleto informativo general y de las normas de régimen interior del Centro penitenciario de que se trate, que el Centro Directivo de la Administración Penitenciaria correspondiente editará necesariamente en castellano y en la lengua cooficial de la Comunidad Autónoma donde radique el Centro penitenciario.

2. A los internos extranjeros se les informará, además, de la posibilidad de solicitar la aplicación de tratados o convenios internacionales suscritos por España para el traslado a otros países de personas condenadas, así como de la sustitución de las penas impuestas o a imponer por la medida de expulsión del territorio nacional, en los casos y con las condiciones previstas por las leyes. Igualmente, se les facilitará la dirección y el número de teléfono de la representación diplomática acreditada en España del país correspondiente.

3. A estos efectos, el mencionado Centro Directivo procurará editar folletos de referencia en aquellos idiomas de grupos significativos de internos extranjeros en los Establecimientos españoles. A los extranjeros que desconozcan los idiomas en que se encuentre editado el folleto se les hará una traducción oral de su contenido por los funcionarios o internos que conozcan la lengua del interesado y, si fuese necesario, se recabará la colaboración de los servicios consulares del Estado a que aquél pertenezca.

4. En todo caso, a aquellos internos españoles o extranjeros que no puedan entender la información proporcionada por escrito, les será facilitada la misma por otro medio adecuado.

5. En el departamento de ingresos y en la Biblioteca de cada Establecimiento habrá, a disposición de los internos, varios ejemplares de la Ley Orgánica General Penitenciaria, del Reglamento Penitenciario y de las normas de régimen interior del Centro.

La Administración procurará proporcionar a los internos extranjeros textos de la Ley Orgánica General Penitenciaria y de su Reglamento de desarrollo en la lengua propia de su país de origen, a cuyo fin recabará la colaboración de las autoridades diplomáticas correspondientes."

Con respecto a este derecho, debo decir que, en mi opinión, el artículo 52 del RP no se hace efectivo en realidad, dada la gran diversidad lingüística que se da en nuestro sistema penitenciario. Además, a causa de esta diversidad, la propia Administración de Extranjería desconoce en gran parte los trámites a realizar para cada uno de los diferentes extranjeros penados. Ni mencionar tiene que, aproximadamente el $20 \%$ de los extranjeros penados no hablen el castellano y casi un $30 \%$ sólo lo entienda, con la consiguiente dificultad que esta situación de indefensión conlleva para ellos.

Consecuencia del no disfrute de este derecho sería por ejemplo, el no poder informar al recluso, por cualquier barrera lingüística, de la posibilidad de sustitución de las penas privativas de libertad inferiores a seis años por la expulsión o cualquier otra cuestión que pueden afectar al cumplimiento de su pena privativa de libertad y que sin duda puede mermar las eficacia de las garantías procesales en el cumplimiento de su pena.

\section{B.2. Derecho a la Educación.}

Artículo 26.1 de la declaración Universal de los Derechos Humanos dispone que, 
"Toda persona tiene derecho a la educación. La educación debe ser gratuita, al menos en lo concerniente a la instrucción elemental y fundamental. La instrucción elemental será obligatoria. La instrucción técnica y profesional habrá de ser generalizada; el acceso a los estudios superiores será igual para todos, en función de los méritos respectivos."

Así mismo, el artículo 2 del Reglamento Penitenciario dispone que "La actividad penitenciaria tiene como fin primordial la reeducación y reinserción social de los sentenciados a penas y medidas de seguridad privativas de libertad, así como la retención y custodia de los detenidos, presos y penados y la asistencia social de los internos, liberados y de sus familiares"

Uno de los componentes más necesarios para la consecución de la reinserción del recluso en general, y del recluso extranjero en particular, es inequívocamente la educación, y que al igual que hemos comentado en el derecho a la información, se encontrará con la misma barrera lingüística que este, el idioma. Precisamente, porque los reclusos que, no solo no hablan nuestro idioma, sino que además difieren en muchas ocasiones en la cultura y en la religión, merecen que sus necesidades especiales queden cubiertas y se garanticen la igualdad de trato y oportunidades con el resto de los reclusos.

Por ello la Administración penitenciaria debe de procurar facilitar a los internos extranjeros los medios apropiados para aprender el idioma castellano además de la lengua cooficial de la CCAA donde este el centro penitenciario donde cumpla condena.

A pesar de todos los programas educativos generales y específicos como por ejemplo formación en idiomas, educación primaria, alfabetización, formación multicultural, profesional y enseñanzas superiores cuyo objetivo es facilitar la reinserción del interno, a pesar de todas las recomendaciones de la Dirección General de Instituciones Penitenciarias, un gran porcentaje de presos extranjeros salen de prisión sin hablar castellano. Evidentemente esto es algo primordial, si lo que queremos es reinsertar al recluso extranjero y redirigirlo a una inserción laboral y social en las mismas condiciones que a un nacional.

\section{B.3. Derecho a la asistencia sanitaria.}

Según el artículo 208.sobre prestaciones sanitarias, el Reglamento penitenciario establece que:

"1. A todos los internos sin excepción se les garantizará una atención médico-sanitaria equivalente a la dispensada al conjunto de la población. Tendrán igualmente derecho a la prestación farmacéutica y a las prestaciones complementarias básicas que se deriven de esta atención.

2. Las prestaciones sanitarias se garantizarán con medios propios o ajenos concertados por la Administración Penitenciaria competente y las Administraciones Sanitarias correspondientes."

Del artículo mencionado en el párrafo anterior, podríamos entender, que efectivamente no existe ningún tipo de distinción ni discriminación entre nacionales y extranjeros. Otra cosa en ahondar en el tema, y preguntarnos si los extranjeros regulares e irregulares tienen los mismos derechos, en cuanto a asistencia sanitaria se refiere.

De hecho el artículo 12. De la LOEX (Modificado por el Real Decreto-ley 16/2012) Sobre asistencia sanitaria dice que "Los extranjeros tienen derecho a la asistencia sanitaria en los términos previstos en la legislación vigente en materia sanitaria." Y es aquí donde debemos pararnos y recapacitar. Según el Real Decreto-ley 16/2012,'Los extranjeros no registrados ni autorizados como residentes en España, recibirán asistencia sanitaria en las siguientes modalidades: 
a) De urgencia por enfermedad grave o accidente, cualquiera que sea su causa, hasta la situación de alta médica.

b) De asistencia al embarazo, parto y postparto.

En todo caso, los extranjeros menores de dieciocho años recibirán asistencia sanitaria en las mismas condiciones que los españoles."

Es decir, para recibir cualquier otro tratamiento que no sea de urgencia, es requisito indispensable que el extranjero debe estar regularizado.

Estas limitaciones a la asistencia sanitaria no debería obviar las consecuencias sociosanitarias que puede generar entre la población extranjera, sobre todo si esta privada de libertad.

Como bien apuntan Alfonso Ortega, Antonio López Álvarez y Lerdys Saray Heredia Sánchez, en su comunicación sobre "El acceso a la asistencia sanitaria de los extranjeros irregulares en España", "La limitación del acceso a la sanidad para determinados colectivos, puede afectar a la salud de los mismos y a la de toda la sociedad, y redundar en perjuicio de la integración de los primeros. (...) la vinculación entre el principio rector del art. $43 \mathrm{CE}$ y el art. $15 \mathrm{CE}$ que recoge el derecho fundamental a la vida y a la integridad física y moral, resulta evidente que los intereses generales y públicos, vinculados a la promoción y garantía del derecho a la salud, son intereses asociados a la defensa de bienes constitucionales particularmente sensibles.

Ciertos colectivos, en particular los inmigrantes sin permiso de residencia, verán notablemente afectada su salud si se les impide el acceso a los servicios sanitarios públicos de forma gratuita, lo que repercutiría, no sólo en su estado de salud individual, sino en la prevención de la propagación de determinadas enfermedades infecto contagiosas, afectando directamente a la salud de toda la sociedad".

Preguntémonos, si un extranjero no tiene el mismo derecho a su integridad física sólo por el mero hecho de no estar en su país. La respuesta es fácil si nos fijamos en la Constitución o en la declaración de los Derechos Humanos.

Aun así, tenemos una Ley basada en la igualdad para todos y en la no discriminación. Sin embargo, existen otras Leyes y Reglamentos que restringen los derechos Humanos de los ciudadanos por su condición de extranjero y más si es también irregular.

\section{B.4. Derecho a la documentación en prisión.}

La mayoría de personas extranjeras cuando entran en prisión no conocen su situación penitenciaria administrativa, ni si quiera cómo se desarrolla el proceso penal en el que están incursos, lo cual les provoca una situación de total indefensión.

Una de las primeras dificultades con las que se va a encontrar el interno extranjero, es que solo por estar en prisión se le va a denegar casi automáticamente el permiso de residencia y/o trabajo.

Este derecho es un derecho de vital importancia dado que su disfrute diferirá según la situación administrativa y penitenciaria de cada recluso extranjero.

El que el recluso extranjero disponga de documentación, será condicionante a lo largo del todo el proceso, ya que de ello dependerá la concesión de la libertad condicional en su país, la concesión de permisos y la sustitución de pena por expulsión entre otras.

B.5. Derecho a permisos de salidas y a la libertad condicional.

En teoría, la Ley Orgánica General Penitenciaria no determina ningún obstáculo para el disfrute de los permisos de salida ordinarios dependiendo de la nacionalidad o la situación administrativa del recluso (art. 47.2). 
Además, el artículo 156.1 de Reglamento Penitenciario dispone que, "El informe preceptivo del Equipo Técnico será desfavorable cuando, por la peculiar trayectoria delictiva, la personalidad anómala del interno o por la existencia de variables cualitativas desfavorables, resulte probable el quebrantamiento de la condena, la comisión de nuevos delitos o una repercusión negativa de la salida sobre el interno desde la perspectiva de su preparación para la vida en libertad o de su programa individualizado de tratamiento." Es decir, que teóricamente no se tiene en cuenta la nacionalidad para la concesión de los permisos de salida por parte de equipo técnico.

No obstante, la Instrucción 3/2008 de "Salidas de internos de los centros penitenciarios", añade un matiz negativo introduciendo una variable de riesgo en la concesión de los permisos de salida, y por consiguiente a la libertad condicional de los internos extranjeros que se ve reflejada en una mayor concesión de permisos a los nacionales que a los reclusos extranjeros.

El permiso de salida y la concesión de libertad condicional es una forma de sobrellevar la vida en prisión, así como mejorar los vínculos familiares y sociales. Es fuente de motivación para los reclusos y es parte fundamental para la posterior resocialización y reinserción del mismo.

Sin embargo, diariamente nos encontramos con la denegación casi automática de los permisos de salida y de libertado condicional. De hecho, como regla general está justificada la no concesión de permisos de salida, alegando que hay que evaluar la situación del recluso, y si es poseedor de una orden de expulsión.

Por esta razón, es sumamente importante que los internos privados de libertad renueven su documentación.

Esto nos lleva preguntarnos en qué medida se facilita a los internos extranjeros la solicitud y renovación de su permisos de residencia y/o trabajo. La respuesta desgraciadamente no tiene un matiz positivo, debido al desconocimiento de la documentación a presentar, la dificultad y en ocasiones imposibilidad de acceder a la información de los tramites, el requerimiento del cuerpo policial para realizar trámites como la estampación de huellas, y sobre todo la exigencia de la presentación personal del recluso, evidentemente imposible.

Mientras que para los reclusos nacionales la obtención de la libertad condicional son sólo meros trámites, para los reclusos extranjeros se convierte en todo un viacrucis, ya que la situación de irregularidad administrativa en la que pueden recaer una vez dentro de prisión, les imposibilita el comienzo del proceso de reinserción y resocialización, que tiene como requisito fundamental la documentación administrativa en regla.

Es lógico pensar, como decíamos anteriormente, que los reclusos extranjeros con más de un año de pena, acabaran su condena inmersos en una situación de vulnerabilidad e irregularidad.

Si de verdad en objetivo de la privación de libertad es la reinserción y la resocialización de los internos deberían de poner más medios y buscar alternativas para que todos, nacionales y extranjeros, irregulares y regulares puedan acceder a dicho fin.

\section{B.6. Derecho al trabajo.}

Otro problema aparece cuando, tras finalizar el periodo de libertad condicional, el extranjero no puede proseguir con el permiso administrativo que le permitía trabajar, debido a que ya no se encuentra en una situación de "residencia judicial" y, además, no se les permite poder solicitar un nuevo permiso de residencia por contar con antecedentes penales.

El artículo 25.2 de la Constitución Española establece el derecho, de los condenados, extranjeros o no, a penas de prisión que estuvieren cumpliendo las mismas, a un trabajo 
remunerado y a los beneficios correspondientes de la Seguridad Social, así como al acceso a la cultura y al desarrollo integral de su personalidad.

Además el artículo 13.1 de nuestra Norma Fundamental garantiza igualmente a los extranjeros en los términos que establezcan los Tratados y la Ley.

Como estamos viendo a lo largo de este análisis, el disfrute de algunos derechos viene condicionado por la situación administrativa de regularidad o irregularidad del recluso.

Este derecho, como no, tiene también como condicionante la posesión del permiso de residencia que además viene de la mano del permiso de trabajo.

El trabajo es considerado uno de los instrumentos, si no el más importante, para una correcta reinserción social y laboral, ya que en numerosas ocasiones la falta de trabajo es lo que ha llevado a la persona a delinquir, y consecuentemente a estar en prisión. La falta de armonización entre las normas de extranjería y las penitenciarías hace que, conciliar los derechos de los extranjeros con el disfrute de los mismos se casi imposible.

\section{B.7. Mención al no acceso a prestación por desempleo}

Según el art. 36.5 LOEX 2/2009 "el trabajador que carezca de autorización de residencia y trabajo no podrá obtener prestaciones por desempleo".

Ya hemos podido observar a lo largo de este análisis, que el disfrute de muchos derechos y en particular al derecho a la no discriminación, versa en torno al acceso o renovación de la documentación. De nuevo, vuelve a vulnerarse este derecho de no discriminación, ya que una vez finalizada la condena, si no han accedido o han renovado su documentación, cosa fácil si han estado privados de libertad más de un año, no se les reconocerá esta prestación.

\section{CONSECUENCIAS DE LA EXCARCELACIÓN}

En lo que atañe a este punto, realizaremos un estudio sobre las actuales vías de excarcelación tales como la famosa "expulsión como sustitutivo penal", el cumplimiento de la condena en su país de origen, así como la concesión de la libertad condicional del extranjero en su país de origen. De igual forma daremos un repaso a las posibles consecuencias que los extranjeros privados de libertad padecen tras la excarcelación.

La Ley Orgánica 5/2010 que ha modificado el Código Penal de 1995, que introdujo modificaciones en materia de sustitución de penas por expulsión, que se regula en el artículo 89 y que establece que, "Las penas privativas de libertad inferiores a seis años impuestas a un extranjero no residente legalmente en España serán sustituidas en la sentencia por su expulsión del territorio español, salvo que el Juez o Tribunal, previa audiencia del penado, del Ministerio Fiscal y de las partes personadas, de forma motivada, aprecie razones que justifiquen el cumplimiento de la condena en un centro penitenciario en España.” Además en su apartado segundo se articula que "el extranjero no podrá regresar a España en un plazo de cinco a diez años, contados desde la fecha de su expulsión, atendidas la duración de la pena sustituida y las circunstancias personales del penado."

\section{A) La expulsión como sustitutivo penal}

La medida de expulsión de extranjeros como medida sustitutiva de penas privativas de libertad desencadena un continuo debate doctrinal y jurisprudencial, que no ha hecho sino tratar de forma desigual y totalmente desproporcionada a este colectivo.

Actualmente, el Código Penal prevé la posibilidad de sustituir una pena inferior a seis años de cárcel por la expulsión del territorio nacional cuando el condenado sea un ciudadano 
extranjero «no residente legalmente», el cual no tiene prácticamente ninguna posibilidad de permanecer en el país.

Así el art.89 del vigente Código Penal establece que "1. Las penas privativas de libertad inferiores a seis años impuestas a un extranjero no residente legalmente en España serán sustituidas en la sentencia por su expulsión del territorio español, salvo que el Juez o Tribunal, previa audiencia del penado, del Ministerio Fiscal y de las partes personadas, de forma motivada, aprecie razones que justifiquen el cumplimiento de la condena en un centro penitenciario en España."

Por tanto, la pena privativa de libertad, se sustituye en su totalidad por la expulsión del territorio nacional, hasta ahora solo dirigido al residente no legal, es decir, un de los colectivos más vulnerables e indefensos en nuestro país.

Dicho artículo ha sufrido considerables modificaciones, debido a la desproporcional sanción que sufre el colectivo de extranjeros en esta situación y que además no es en absoluto equiparable con la situación de los reclusos autóctonos.

Para rizar más el rizo, el año pasado el Consejo de Ministros aprobó un anteproyecto de Ley para una reforma del Código Penal, donde la sustitución de la pena de prisión de más de un año por expulsión del territorio español, se ampliaba a todos los extranjeros, independientemente de su situación administrativa y jurídica, es decir con o sin autorización de residencia.

Este anteproyecto de Ley para la de reforma del Código Penal, introduce un matiz indiscutiblemente perjudicial, nocivo y contraproducente del principio de proporcionalidad, ya que extiende a "todos los extranjeros", y ya no sólo a los no residentes legalmente, la posibilidad de ser expulsado si es condenado a más de un año por un delito catalogado como menos grave.

Esta nueva posibilidad, abre el camino para que sean expulsados los inmigrantes con independencia de su situación, cuando se les imponga una pena superior al año de cárcel, aunque también es cierto que se establecen excepciones a esa previsión.

Si no fijamos, en que en números casos, el extranjero viene a España por una situación económica precaria, o incluso huyendo de la inestable situación política de su país de origen con la intención de establecerse en España para mejorar su situación. Es triste pensar, que en un país de democracia como es España y viendo en la época que vivimos, cometamos estos actos tan abusivos y desproporcionados. Parece necesario revisar cada expediente individualmente, para comprobar las circunstancias personales de cada individuo y no ceñirnos al automatismo que precede a esta medida de excarcelación como es la expulsión.

Otro principio infringido con esta propuesta de reforma es el principio de no discriminación. Si imaginamos dos personas sin antecedentes penales, una extranjera y otra nacional, los dos totalmente integrados en la sociedad, cometiendo el mismo delito (delito menor) podemos observar claramente la realidad tan dispar entre uno y otro. Seguramente el español, en este caso, quedaría en libertad. En cambio el extranjero se le podría imponer la expulsión, y no solo eso, sino que además tendría una prohibición de entrada en España de hasta 10 años con las consecuencias sociales y familiares que acarrea, y muchas veces sin tener en cuenta las cargas familiares, el arraigo social, etc.

STS n $n^{\circ} 853 / 2010$, de 15 de octubre, establece "No cabe duda que la aplicación de los dos primeros párrafos del art. 89 del C. Penal a partir de la reforma por Ley Orgánica 11/2003 ha evidenciado su difícil compatibilidad con los fines del ordenamiento jurídico-penal y ha obligado a seguir diferentes criterios interpretativos dependiendo de la cuantía de la pena privativa de libertad impuesta en la sentencia. Y así, en lo que respecta a la ejecución de las 
penas de prisión inferiores a dos años, al hallarnos en un tramo donde el texto penal prioriza, la reinserción del penado a través de la suspensión de condena y de los sustitutivos penales, ha sido preciso individualizar el entorno personal y social del extranjero para ajustar la aplicación del art. 89 a las exigencias del principio de proporcionalidad".

\section{B) El cumplimiento de condena en el país de origen}

El cumplimiento de condena en el país de origen viene regulado por el Convenio Estrasburgo, así como por Tratados bilaterales existentes. Esta regulación, da la posibilidad a personas extranjeras condenadas, en este caso en España, a cumplir la condena en su país de origen.

Sobre esta medida de excarcelación hay que decir que, sin duda, es un proceso excesivamente largo, debido a la falta de coordinación de las Administraciones de los distintos países y a la extrema lentitud en sus actuaciones. Además, al preso que está a la espera de información acerca de su situación administrativa, que nunca llega, y del estado del proceso de traslado, se le crea un continuo estrés, absolutamente innecesario.

Aun así, el traslado del recluso, para el cumplimiento de su condena en su país de origen, parece un mecanismo más acorde con la finalidad de la pena, ya que el objetivo es que se cumpla la pena en un entorno donde el preso se sienta "mejor" o al menos donde se vaya a producir la reinserción.

\section{C) La libertad condicional del extranjero en su país de origen}

La libertad condicional del extranjero en su país de origen se regula en el artículo 197 del Reglamento Penitenciario que establece en su punto 1 que:

"1. En el caso de internos extranjeros no residentes legalmente en España o de españoles residentes en el extranjero, previa conformidad documentada del interno, se elevará al Juez de Vigilancia su expediente de libertad condicional recabando autorización para que aquél pueda disfrutar de esta situación en su país de residencia, así como de las cautelas que hayan de adoptarse, en su caso, al objeto de que dicha libertad se disfrute efectivamente en el país fijado. A estos efectos, y siempre que las normas de Derecho Internacional lo permitan, se podrá solicitar a las autoridades competentes del Estado del país fijado la aplicación de las medidas de seguimiento y control de la libertad condicional previstas en su legislación interna."

Dicho esto, es obvio que nuestro ordenamiento jurídico se escuda también en este artículo para la no reinserción de los extranjeros que cumplen condena en España. De igual forma, pone más obstáculos administrativos, para que el colectivo de reclusos extranjeros pueda ser reinsertado y resocializado en el país donde han elegido para tener una mejor vida. Es por todos sabido, que una vez cumplida la condena existe una gran dificultad y muchas veces imposibilidad para permanecer en España.

\section{D) Consecuencias tras la excarcelación}

Sin duda, la consecuencia más grave tras la extinción o cumplimiento de la condena, es la expulsión del territorio nacional.

Según el art. 57.2 de la Ley de Extranjería articula que, "constituirá causa de expulsión, previa tramitación del correspondiente expediente, que el extranjero haya sido condenado, dentro o fuera de España, por una conducta dolosa que constituya en nuestro país delito sancionado con pena privativa de libertad superior a un año, salvo que los antecedentes penales hubieran sido cancelados". 
Por tanto, esta pena de más de un año de prisión será el motivo de la expulsión, que además conllevará la perdida de la autorización para poder residir legalmente en España.

Podemos decir de esta manera, que el extranjero en situación irregular se le expulsa del territorio nacional y el extranjero legal penado cumple doble condena, una en la que tiene que permanecer entre rejas y otra posterior, que no es sino la expulsión de España.

La Constitución de 1978 no incluye explícitamente el principio "non bis in idem". Por el contrario la doctrina protege y apoya este principio, ya que, una doble condena como la que sufre un extranjero privado de libertad en España, se entiende que va en contra del principio de legalidad del artículo 25 de la Constitución.

El Tribunal Constitucional en su Sentencia 77/1983 expone que, "el principio non bis in ídem determina una interdicción de la duplicidad de sanciones, administrativas y penales, respecto de unos mismos hechos, pero conduce también a la imposibilidad de que cuando el ordenamiento permite una dualidad de procedimiento, y en cada uno de ellos ha de producirse un enjuiciamiento y calificación de unos mismos hechos, el enjuiciamiento y la calificación que en el plano jurídico puedan producirse, se hagan con independencia, si resultan de la aplicación de normativa diferente, pero que no puede ocurrir lo mismo en lo que se refiere a la apreciación de los hechos, pues es claro que unos mismos hechos no pueden existir y dejar de existir para los órganos del Estado".

Afortunadamente no todos las expulsiones llegan a producirse, aunque no por ello podemos decir que es bueno o justo. El extranjero, una vez cumplida su condena, sin expulsión, sin documentación, queda en una situación administrativa de irregularidad, vulnerabilidad e indefensión absoluta y que además se hace notoriamente inaceptable en un Estado de Derecho como el nuestro.

\section{CONCLUSIONES}

Tras la elaboración del presente estudio -y antes de cerrar el trabajo con las correspondientes conclusiones-, es importante destacar que actualmente en España estamos acostumbrados a ver en prensa, televisión, redes sociales y otros medios de comunicación, noticias sobre inmigración, en muchas ocasiones relacionadas con los delitos. Del mismo modo, es cierto que nuestra sociedad, lamentablemente, tiende a pensar que inmigración y criminalidad van unidos en un "pack", pero en realidad, no creo se haya podido contrastar la veracidad de este hecho.

A mi juicio, no me parece que exista un colectivo o "nacionalidad" que delinca más que otra. No son los nacionales o los extranjeros (que además, es un colectivo muy heterogéneo) los que delinquen, sino las personas quienes deciden no respetar la Ley, pero nada que ver con el ser extranjero o no. Ser inmigrante no es sinónimo de ser delincuente, ya que el delincuente no nace se hace.

En un estado de democracia como en el que vivimos, deberíamos plantearnos medidas integradoras y socializadoras y no mecanismos encaminados a la exclusión social, como los que rigen actualmente en España y también en Europa. Es totalmente necesaria una sensibilización social y un cambio integrador de las políticas de extranjería.

Para concluir quisiera expresar unas ideas a modo de resumen:

PRIMERA: A lo largo de los últimos años, la población extranjera en general y, por tanto, la población extranjera reclusa en particular ha experimentado un aumento, cuantitativamente hablando. 
SEGUNDA: En general, existe una falsa percepción social que relaciona inmigración y delincuencia, influenciada mayoritariamente por los medios de comunicación, en su mayoría politizados. Sin embargo, una gran variedad de estudios han constatado otra realidad. El nivel de delincuencia no viene influido por la nacionalidad del individuo, sino más bien por otras variables como el desempleo, el desarraigo familiar, el nivel educativo bajo; y es esto en lo que deberíamos centrarnos para disminuir la tasa de delincuencia en España.

Es decir, el aumento de la delincuencia en mayor parte, se debe a una simultaneidad de una serie de circunstancias o variables (de las que hablábamos anteriormente) y que, en varias ocasiones, se dan con mayor asiduidad entre el colectivo de extranjeros que recibimos en España, que con carácter general, solo buscan una oportunidad de mejorar su vida.

TERCERA: De hecho, en lo que al perfil del recluso extranjero se refiere, podemos decir que se trata de varones, mayoritariamente joven, procedentes sobre todo de Marruecos y Latinoamérica y con un nivel de estudio bajo. Estas circunstancias, y la precariedad económica que muchos de estos colectivos padecen, son condicionantes a tener en cuenta.

CUARTA: Debido a la errónea relación entre inmigración y delincuencia y pese a que nuestra Constitución Española de 1978, establece en el Art. 25.2 que "las penas privativas de libertad y las medidas de seguridad están orientadas hacia la reeducación y la reinserción social", el carácter restrictivo de las actuales políticas migratorias ha propiciado que estas políticas migratorias estén basadas en la expulsión del extranjero del territorio nacional. Esto supone un continua incongruencia entre la normativa vigente, que por un lado persigue el ansiado objetivo de reinserción social y reeducación, y por otro lado aplica mecanismos represivos y defensivos dirigidos a evitar la entrada y permanencia de inmigrantes a España.

QUINTA: A pesar de los fundamentos del código penal y la normativa aplicable al cumplimiento de las condenas giran en torno al principio de igualdad, la realidad de nuestras instituciones penitenciarias revela innumerables casos de discriminación y desigualdad en el tratamiento entre nacionales y extranjeros.

SEXTA.: El continuo conflicto entre la Administración de Extranjería y Penitenciaria llega a menoscabar los derechos de los extranjeros que cumplen condena en España, de un colectivo que dada su doble realidad, la de ser extranjero y además estar en prisión, sufre una marginalidad y exclusión social impensable en estos tiempos en un país de derecho y democracia como es España.

SÉPTIMA: Existe una absoluta incongruencia entre el Reglamento Penitenciario que tiene objetivo de reeducación y resocialización, y la realidad de los extranjeros una vez finalizada la condena, ya que una vez extinguida esta es extremadamente complicado permanecer en España. ¿Qué sentido tiene reeducar a una persona cuando se le va a imposibilitar permanecer en el territorio nacional?

Todas estas cuestiones deberían de hacernos pensar y replantearnos las políticas penitenciarias y penales, sin olvidarnos de las no menos importantes, las políticas sociales. Es por tanto necesario que leyes, reglamentos y demás normativa que conforman el ordenamiento jurídico vayan encaminadas en una misma dirección, que sean coherentes, homogéneas y por supuesto acordes a la realidad cultural y lingüística que vivimos actualmente. En definitiva, trabajar duro y estar abiertos a cambios que permitan garantizar los derechos de todas las personas en igualdad de condiciones. 


\section{BIBLIOGRAFÍA}

ABARCA JUNCO, A. P. (2012). Inmigración y extranjería: régimen jurídico básico. Barcelona: Constitución y Leyes.

ALVARADO SÁNCHEZ, R. (2012). Perspectiva histórica y problemas actuales de la Institución Penitenciaria en España. Tesis doctoral. Salamanca: Universidad de Salamanca.

ANGUREL LAMBÁN, M. J. (2012). Extranjeros, cárcel y derechos humanos: una doble marginalidad. Salamanca: Comisión Episcopal de Pastoral Social.

DÍEZ MORRÁS, F. J. (2011). “Inmigración laboral en La Rioja 2010”. En REDUR, 9: 271-307.

GARCÍA ESPAÑA, E. (2012). "Las otras poblaciones presas: mujeres y extranjeros". Universidad de Málaga. En: Revista de derecho penal y criminología, 7: 407-422.

GARCÍA GARCÍA, J. (2006). Extranjeros en prisión: aspectos normativos y de intervención penitenciaria. Barcelona: Congreso penitenciario internacional.

GUTIÉRREZ GUTIÉRREZ, I. (2001). "Constitución española, derechos de los extranjeros". En: Revista Jueces para la Democracia, 41: 19- 22.

HEREDIA SÁNCHEZ, L. S. (2006). "La llegada masiva de inmigrantes a España: varias caras de un mismo problema”. Elche. En: Revista de la Facultad de Ciencias Sociales y Jurídicas, 1: 92-107.

LEGANÉS GÓMEZ, S. (2002). Clasificación penitenciaria, permisos de salida y extranjeros en prisión. Madrid: Dykinson.

LÓPEZ MELERO, M. (2011). Los derechos fundamentales de los presos y su reinserción social. Madrid: Universidad de Alcalá.

ORTEGA GIMÉNEZ, A. (2006). Guía Práctica de los Derechos y Libertades de los Extranjeros y su Integración Social en la Ciudad de Elche. Elche: Editorial Club Universitario.

RODRÍGUEZ YAGÜE, C. (2004). "Derechos de los extranjeros en prisiones españolas: legalidad y realidad". En: Revista General de Derecho Penal, nº 2.

RODRÍGUEZ YAGÜE, C. (2012). "El modelo político-criminal español frente a la delincuencia de inmigrantes”. En: Revista Electrónica de Ciencia Penal y Criminología, 14: 1-42.

SALVADOR CONCEPCIÓN, R. (2012). "La expulsión del extranjero como castigo penal". En: Revista Internacional de Estudios Migratorios, 6: 93-116.

SÁNCHEZ YLLERA, I. (1990). "Extranjeros en prisión: doble condena". En: Revista Jueces para la democracia, 10: 65-70.

\section{Breve currículo:}

\section{Cristina Santacruz Iglesias}

Graduada en Relaciones Laborales y Recursos Humanos por la Universidad Miguel Hernández, diplomada en Relaciones Laborales por la Universidad de Alicante. Docente de Graduado de educación secundaria para adultos (TREFOR). Técnico de investigación sobre el impacto de las redes sociales en la búsqueda activa de empleo (SERVEF). Título de técnico en Orientación Laboral por el Servicio Valenciano de Empleo y Formación. 